\title{
The Brazilian version of the 20-item rapid estimate of adult literacy in medicine and dentistry
}

Agnes Fátima P Cruvinel ${ }^{1}$, Daniela Alejandra C Mendez ${ }^{2}$, Juliana G Oliveira ${ }^{2}$, Eliézer Gutierres ${ }^{2}$, Matheus Lotto $^{2}$, Maria Aparecida A M Machado ${ }^{2}$, Thaís M Oliveira ${ }^{2}$, Thiago Cruvinel ${ }^{\text {Corresp. } 2}$

${ }^{1}$ Department of Public Health/ School of Medicine, Federal University of Fronteira Sul, Chapecó, SC, Brazil

2 Department of Pediatric Dentistry, Orthodontics and Public Health/ Bauru School of Dentistry, University of São Paulo, Bauru, SP, Brazil

Corresponding Author: Thiago Cruvinel

Email address: thiagocruvinel@fob.usp.br

Background: The misunderstanding of specific vocabulary may hamper the patienthealth provider communication. The 20-item Rapid Estimate Adult Literacy in Medicine and Dentistry (REALMD-20) was constructed to screen patients by their ability in reading medical/dental terminologies in a simple and rapid way. This study aimed to perform the cross-cultural adaptation and validation of this instrument for its application in Brazilian dental patients. Methods: The cross-cultural adaptation was performed through conceptual equivalence, verbatim translation, semantic, item and operational equivalence, and back-translation. After that, 200 participants responded the adapted version of the REALMD-20, the Brazilian version of the Rapid Estimate of Adult Literacy in Dentistry (BREALD-30), ten questions of the Brazilian National Functional Literacy Index (BNFLI), and a questionnaire with socio-demographic and oral health-related questions. Statistical analysis was conducted to assess the reliability and validity of the REALMD-20 $(P<0.05)$. Results: The sample was composed predominantly by women (55.5\%) and white/brown (76\%) individuals, with an average age of 39.02 years old $( \pm 15.28)$. The average REALMD20 score was 17.48 ( \pm 2.59 , range $8-20)$. It displayed a good internal consistency (Cronbach's alpha $=0.789$ ) and test-retest reliability $(\mathrm{ICC}=0.73 ; 0.66-0.79,95 \% \mathrm{Cl}$ ). In the exploratory factor analysis, six factors were extracted according to Kaiser's criterion. The factor I (eigenvalue=4.53) comprised four terms - "Jaundice", "Amalgam", "Periodontitis" and "Abscess"- accounted for $25.18 \%$ of total variance, while the factor II (eigenvalue=1.88) comprised other four terms - "Gingivitis", "Instruction", "Osteoporosis" and "Constipation" - accounted for $10.46 \%$ of total variance. The first four factors accounted for $52.1 \%$ of total variance. The REALMD-20 was positively correlated with the BREALD-30 ( $R s=0.73, P<0.001)$ and BNFLI $(R s=0.60, P<0.001)$. The scores were significantly higher among health professionals, more educated people, and individuals who reported good/excellent oral health conditions and who sought preventive dental 
services. Distinctly, REALMD-20 scores were similar between both participants who visited a dentist $<1$ year ago and $\geq 1$ year. Also, REALMD-20 was a significant predictor of selfreported oral health status in a multivariate logistic regression model, considering sociodemographic and oral health-related confounding variables. Conclusion: The Brazilian version of the REALMD-20 demonstrated adequate psychometric properties for screening dental patients in relation to their recognition of health specific terms. This instrument can contribute to identify individuals with important dental/medical vocabulary limitations in order to improve the health education and outcomes in a person-centered care model. 
1 The Brazilian version of the 20-item rapid estimate of adult literacy in medicine and dentistry

2

3

4

5

6

8

\section{Running Head: The Brazilian Version of the REALMD-20}

Agnes Fátima Pereira Cruvinel ${ }^{1}$, Daniela Alejandra Cusicanqui Mendez ${ }^{2}$, Juliana Godoy Oliveira ${ }^{3}$, Eliézer Gutierres ${ }^{4}$, Matheus Lotto ${ }^{5}$, Maria Aparecida Andrade Moreira Machado 6 , Thaís Marchini Oliveira $^{7}$, Thiago Cruvinel ${ }^{8}$

${ }^{1}$ Department of Public Health, School of Medicine, Federal University of Fronteira Sul. Rodovia SC 484 Km 02, Chapecó, 89815-899, Brazil. Phone: +55 4920492600 E-mail: agnes.cruvinel@uffs.edu.br

${ }^{2}$ Department of Pediatric Dentistry, Orthodontics and Public Health, Bauru School of Dentistry, University of São Paulo. Al. Dr. Octávio Pinheiro Brisolla, 9-75, Vila Universitária, Bauru, 17012-901, Brazil. Phone: +55 143235 8318. E-mail: dani.cusicanqui@hotmail.com

${ }^{3}$ Department of Pediatric Dentistry, Orthodontics and Public Health, Bauru School of Dentistry, University of São Paulo. Al. Dr. Octávio Pinheiro Brisolla, 9-75, Vila Universitária, Bauru, 17012-901, Brazil. Phone: +55 143235 8318. E-mail: juliana.godoy.oliveira@usp.br

${ }^{4}$ Department of Pediatric Dentistry, Orthodontics and Public Health, Bauru School of Dentistry, University of São Paulo. Al. Dr. Octávio Pinheiro Brisolla, 9-75, Vila Universitária, Bauru, 17012-901, Brazil. Phone: +55 143235 8318. E-mail: eliezer.gutierres@usp.br

${ }^{5}$ Department of Pediatric Dentistry, Orthodontics and Public Health, Bauru School of Dentistry, University of São Paulo. Al. Dr. Octávio Pinheiro Brisolla, 9-75, Vila Universitária, Bauru, 17012-901, Brazil. Phone: +55 143235 8318. E-mail: matheus.lotto.souza@usp.br

${ }^{6}$ Department of Pediatric Dentistry, Orthodontics and Public Health, Bauru School of Dentistry, University of São Paulo. Al. Dr. Octávio Pinheiro Brisolla, 9-75, Vila Universitária, Bauru, 17012-901, Brazil. Phone: +55 143235 8224. E-mail: mmachado@fob.usp.br

${ }^{7}$ Department of Pediatric Dentistry, Orthodontics and Public Health, Bauru School of Dentistry, University of São Paulo. Al. Dr. Octávio Pinheiro Brisolla, 9-75, Vila Universitária, Bauru, 17012-901, Brazil. Phone: +55 143235 8224. E-mail: marchini@usp.br

${ }^{8}$ Department of Pediatric Dentistry, Orthodontics and Public Health, Bauru School of Dentistry, University of São Paulo. Al. Dr. Octávio Pinheiro Brisolla, 9-75, Vila Universitária, Bauru, 17012-901, Brazil. Phone: +55 143235 8318. E-mail: thiagocruvinel@fob.usp.br

\section{Corresponding author}

Thiago Cruvinel

Department of Pediatric Dentistry, Orthodontics, and Public Health

Bauru School of Dentistry, University of São Paulo

Alameda Dr. Octávio Pinheiro Brisolla, 9-75, Vila Universitária

17012-901, Bauru - SP, Brazil

Telephone: +55 1432358318

Telefax: +55 1432234679

Email: thiagocruvinel@fob.usp.br 
The Brazilian version of the 20-item rapid estimate of adult literacy in medicine and dentistry

49

50 ABSTRACT

51 Background: The misunderstanding of specific vocabulary may hamper the patient-health 52 provider communication. The 20-item Rapid Estimate Adult Literacy in Medicine and Dentistry 53 (REALMD-20) was constructed to screen patients by their ability in reading medical/dental 54 terminologies in a simple and rapid way. This study aimed to perform the cross-cultural 55 adaptation and validation of this instrument for its application in Brazilian dental patients. 56 Methods: The cross-cultural adaptation was performed through conceptual equivalence, 57 verbatim translation, semantic, item and operational equivalence, and back-translation. After 58 that, 200 participants responded the adapted version of the REALMD-20, the Brazilian version 59 of the Rapid Estimate of Adult Literacy in Dentistry (BREALD-30), ten questions of the 60 Brazilian National Functional Literacy Index (BNFLI), and a questionnaire with socio61 demographic and oral health-related questions. Statistical analysis was conducted to assess the 62 reliability and validity of the REALMD-20 $(P<0.05)$. Results: The sample was composed 63 predominantly by women $(55.5 \%)$ and white/brown $(76 \%)$ individuals, with an average age of 6439.02 years old $( \pm 15.28)$. The average REALMD-20 score was $17.48( \pm 2.59$, range $8-20)$. It 65 displayed a good internal consistency (Cronbach's alpha $=0.789)$ and test-retest reliability (ICC $66=0.73 ; 0.66-0.79,95 \% \mathrm{CI})$. In the exploratory factor analysis, six factors were extracted 67 according to Kaiser's criterion. The factor I (eigenvalue=4.53) comprised four terms 68 "Jaundice", "Amalgam", "Periodontitis" and "Abscess"- accounted for $25.18 \%$ of total 69 variance, while the factor II (eigenvalue=1.88) comprised other four terms - "Gingivitis", 70 "Instruction", "Osteoporosis" and "Constipation" - accounted for 10.46\% of total variance. The 71 first four factors accounted for $52.1 \%$ of total variance. The REALMD-20 was positively 72 correlated with the BREALD-30 $(R s=0.73, P<0.001)$ and BNFLI $(R s=0.60, P<0.001)$. The 73 scores were significantly higher among health professionals, more educated people, and 74 individuals who reported good/excellent oral health conditions and who sought preventive dental 75 services. Distinctly, REALMD-20 scores were similar between both participants who visited a 76 dentist $<1$ year ago and $\geq 1$ year. Also, REALMD-20 was a significant predictor of self-reported 
77 oral health status in a multivariate logistic regression model, considering socio-demographic and 78 oral health-related confounding variables. Conclusion: The Brazilian version of the REALMD-

7920 demonstrated adequate psychometric properties for screening dental patients in relation to 80 their recognition of health specific terms. This instrument can contribute to identify individuals 81 with important dental/medical vocabulary limitations in order to improve the health education 82 and outcomes in a person-centered care model.

83

\section{INTRODUCTION}

85 Developing countries have a large percentage of people living in areas with deprivation of income 86 and other social rights, such as education and healthcare [1]. This situation increases the prevalence 87 of adults with difficulties in word recognition, reading, writing, document interpretation, 88 quantitative analysis, communication skills, and conceptual knowledge [2,3]. In 2011, 27\% 89 Brazilian people between 15 and 64 year olds were considered functional illiterates, varying from 90 11\% (15-24 year olds) to 52\% (50-64 year olds) [4]. These limitations hamper the health literacy 91 levels of patients [5] and, consequently, their adherence with healthy lifestyle, and their 92 engagement to shared health decision-making process, prevention and treatment of diseases [6-9].

93 The health literacy is a powerful predictor of health status in comparison to more distal socio94 demographic variables, such as age, income, occupation, education, race and ethnic group [10,11]. 95 Low health literacy increases the hospitalization rates, the underuse of preventive services, and the 96 misinterpretation of health information [3,12], leading to poor oral health conditions, and an 97 inadequate self-perception of dental treatment needs and dental utilization $[13,14]$.

98 Additionally, individuals with low health literacy express impatience and frustration in using 99 written documents, spending a considerable time filling health forms with incomplete and/or 100 incorrect data [10]. Therefore, clinicians should employ health literacy-based practices in their 101 daily routine focused on improving health outcomes [15]. Thereby, the availability of instruments 102 to identify individuals with low health literacy is fundamental. Despite the development of several 103 health literacy-based instruments, these tools are more restricted to English-speaking countries, 104 especially to the U.S. [16,17]. In Brazil, there are only two validated instruments based on the 105 recognition of words. The Rapid Estimate of Adult Literacy in Dentistry (BREALD-30) [18] 106 comprises exclusively dental terms, while the Short Assessment of Health Literacy for Portuguese- 
107 Speaking Adults (SAHLPA) [19] presents a list of specific medical terms that need to be 108 interpreted.

109 Based on the knowledge of the association between medical and dental conditions, such as poor 110 mastication and the impairment of cognitive function [20], adequate periodontal status and 111 glycemic control [21], the diagnosis of chronic periodontitis and the development of atherosclerotic 112 heart disease [22], and periodontal disease and obesity [23], the process of health education 113 requires the basic domain of a cross-disciplinary vocabulary by patients, since the 114 misunderstanding of specific terms could hamper the prevention of oral diseases, also impacting 115 negatively the systemic health, and vice-versa [24]. Hence, it would be desirable the availability of 116 an instrument that evaluates the dynamic interplay of medical/dental words in the patient-health 117 professional communication. In this context, the 20-item Rapid Estimate Adult Literacy in 118 Medicine and Dentistry (REALMD-20) is singular, with the aim of screening individuals by their 119 ability in reading medical and dental terminologies simultaneously, in a simpler and faster way, 120 requiring minimal training of its applicants [12,24]. For instance, the REALMD-20 uses only 20 121 terms to analyze effectively the recognition of words from two health fields, differently of the other 122 tools aforementioned.

123 Taking into consideration (1) the lack of a Brazilian Portuguese health literacy instrument focused 124 on the simultaneous recognition of dental and medical terms, and (2) the singularity and 125 advantages of the use of REALMD-20 to recognize people with limited health literacy, this study 126 aimed to perform the Brazilian cross-cultural adaptation and validation of this instrument for its 127 application to dental patients in clinical studies.

128

\section{MATERIALS \& METHODS}

130 This study was previously authorized by the authors of the original REALMD-20 [24], and 131 approved by the Human Research Ethics Committee of the Bauru School of Dentistry, University 132 of São Paulo, Brazil (\#CAAE 34539714.7.0000.5417), in accordance with the ethical standards of 133 the Declaration of Helsinki.

134

\section{Cross-Cultural Adaptation}


136 The cross-cultural adaptation was performed as described by Herdman et al. [25] and Reichenheim

137 and Moraes [26]. This process was divided in six distinct steps, as follows: a) conceptual

138 equivalence, b) verbatim translation, c) semantic equivalence, d) item equivalence, e) operational

139 equivalence, and f) back-translation.

\section{Conceptual Equivalence}

141 Two examiners with expertise in health education analyzed the conceptual framework of the 142 REALMD-20, considering its application adequate to screening Brazilian Portuguese native 143 speakers for limited health literacy levels. The elements analyzed are summarized below:

144

145

146

147

148

149

150

151

152

153

154

155

156

157

158

159

160

161

162

163

164

165

(i)

the instrument was developed with basis on the concept of health literacy incorporated into The Patient Protection and Affordable Care Act (P.L. 111-148), as follows: "health literacy is the degree to which individuals have the capacity to obtain, process, and understand basic health information and services needed to make appropriate health decisions" [27]. This definition can be considered appropriate and valid for unlimited cultures;

(ii) the REALMD-20 is limited in evaluating the capacity of reading health terms, one aspect of the constellation of abilities needed to construct an adequate health literacy level. Despite this disadvantage, written materials are still the most common source of health information, especially after the advent of the Internet [28]. In this context, the relevance of this instrument is supported by its purpose of screening individuals for limited health literacy smoothly, since the ability tested is essential to the acquisition of medical and/or dental knowledge. In addition, the correct reading might indicate indirectly the prior knowledge of the person on specific health terms.

(iii) the structure of the REALMD-20 takes into account that the misconception of medical issues could prevent the successful dental interventions, and vice-versa. This consideration could add significant data and novel interpretations in clinical and epidemiological studies.

\section{Verbatim Translation, Semantic and Item Equivalences}

Initially, the REALMD-20 was literally translated to Brazilian Portuguese by three bilingual health professionals. After the analysis of the independent translations, the semantic of words "Insurance" and "Directed" seemed non-representative of health-related terms for Brazilian people. Then, they 
166 were replaced by equivalent terms in Portuguese, with the aid of a specialist in language and 167 communication. The term "Insurance" was replaced by the single word Covenant ("Convênio") 168 based on its dictionary definition, while the term "Directed" was replaced by the word Instruction 169 ("Instrução"), its synonym cited in the instrument Short Assessment of Health Literacy (S-SAHL) 170 [29].

171 Operational Equivalence and Back-Translation

172 This stage is crucial to apply the instrument for a reduced sample in a near-real condition, in order 173 to detect possible influences of the instrument's characteristics on the performance of target 174 individuals [26]. The first version of the REALMD-20 consisted of translated/adapted terms that 175 were still ordered similarly to the original version. It was applied for ten adults who attended the 176 dental clinics of the Bauru School of Dentistry, University of São Paulo, Brazil. They received 177 information concerning the aims of the study and signed a statement of informed consent to the 178 inclusion of material pertaining to themselves, with the maintenance of anonymous information 179 and no identification of their acknowledge via the paper.

180 The influences of the layout and format of the words/instructions, the application setting, and the 181 way of application of the instrument on the results were analyzed in a pre-test by face-to-face 182 interview, when the individuals were asked to report their impression and contributions for 183 improving the application of the tool. This phase was also used as an additional measure to 184 determine the reading difficulty of each word [26], as described below.

185 The respondents were predominantly composed by white-brown (70\%) and women (80\%), with a 186 mean age of 41.8 years and distinct educational levels, varying from primary education to tertiary 187 education. They considered the instrument as a simple and easy tool to disclose the difficulties of 188 patients in understanding health instructions. However, the terms related to "Abscess", 189 “Calculus”, “Allergic”, “Instruction”, “Constipation”, "Extraction”, “Jaundice”, "Periodontitis”, 190 “Amalgam”, “Gingivitis", and “Osteoporosis” were mispronounced by at least one subject. In this 191 scenario, three subjects read two or more listed terms incorrectly. The most reading errors were 192 committed by two subjects with the lowest levels of education ( $<4$ and $<8$ years of school).

193 Subsequently, the terms were arranged in order of increasing reading difficulty, considering (a) the 194 number of syllables, (b) the presence of consonant clusters, (c) the word accentuation, (d) the prior 195 knowledge of individuals, and (e) the results obtained during the pre-test. To guarantee the 
196 maintenance of cultural and conceptual correspondence between the original and adapted versions, 197 another two independent translators back-translated the instrument to English.

\section{Validation}

200 Two hundred adults with 18-80 years old from different educational backgrounds were enrolled in 201 this study. They were recruited among patients who attended in the dental clinics of the Bauru 202 School of Dentistry, University of São Paulo, Brazil. Illiterates, non-native Brazilian Portuguese 203 speakers, patients with cognitive, vision, or hearing impairment, and subjects intoxicated by 204 alcohol and/or drugs were not included in the sample. The participants were also informed about 205 the aims of the study and signed a statement of consent. For more details about demographic 206 characteristics of the sample, please see the results.

207 Six trained investigators asked participants to respond the Brazilian version of the REALMD-20, 208 the Brazilian version of the Rapid Estimate of Adult Literacy in Dentistry (BREALD-30) [18], ten 209 questions from the Brazilian National Functional Literacy Index (BNFLI) [30], and a questionnaire 210 about socio-demographic and oral health-related aspects. The investigators were trained in meeting 211 sessions with basis on a document that described all required actions to the correct application of 212 the instruments. These trainings involved the presentation of diverse situations that were discussed 213 among the participants, such as examples of correct and incorrect readings.

214 Initially, the participants were invited to take a seat in a comfortable room. They then were 215 interviewed using a questionnaire containing four socio-demographic questions and three oral 216 health-related questions. Following, they were asked to retain a sheet containing the REALMD-20 217 (Table 1), and read each one of 20 terms aloud. The words clearly and fluidly pronounced received 218 a score of 1, whereas the inability to read (silence), "trial and error", hesitation of reading, 219 mispronunciation or not attempted words received a score of 0 , with an overall score ranging from 2200 to 20 [24]. To determine the test-retest reliability, the REALMD-20 was re-applied to $10 \%$ of 221 sample one month later.

222 Subsequently, the BREALD-30 was applied to evaluate the ability of participants in reading and 223 pronouncing specific dental terms. It comprises 30 words also arranged in order of increasing 
224 reading difficulty. The subjects also received one point for each term read correctly, with total 225 scores ranging from 0 to $30[18]$.

226 Finally, the subjects responded 10 questions of BNFLI. It measures the functional literacy of 227 Brazilian population aged between 15 to 64 year olds [30], by the application of a set of simple 228 tests about the interpretation of figures and documents. In this study, the participants received one 229 point for each right answer, with the overall score varying from 0 to 10.

230

\section{Statistical Analysis}

232 Data were analyzed using the Statistical Package for the Social Sciences (SPSS) version 21.0 $233 \quad\left(\mathrm{IBM}^{\circledR}{ }^{\circledR P S S}{ }^{\circledR}\right.$ Statistics, New York, USA).

234 The exploratory factor analysis (EFA) was conducted to assess the dimensionality of the 235 instrument. The suitability of the dataset for the factor analysis was confirmed by Kaiser-Meyer236 Olkin Measure of Sampling (KMO) ( $>0.60)$, the Barlett's Test of Sphericity $(P<0.05)$, and the 237 value of the determinant of the correlation matrix $(>0.00001)$. The factors were extracted by 238 principal component analysis (PCA), according to Kaiser's criterion (eigenvalue >1.0). The 239 Varimax rotation was applied to minimize the number of variables with high loadings in each 240 factor. The items with communalities and factor loadings $\geq 0.4$ were considered acceptable [31].

241 The internal consistency and the test-retest reliability of the REALMD-20 were determined by 242 Cronbach's alpha and intraclass correlation coefficient (ICC) for absolute concordance, 243 respectively.

244 The Spearman's correlation test determined the convergent validity of the REALMD-20 with the 245 BREALD-30 and the BNFLI. The discriminant validity was detected by Mann-Whitney U test 246 through the comparison of REALMD-20 scores between dichotomized socio-demographic 247 variables and oral health-related aspects, as follows: gender (male/female), age ( $<36$ years-old/ $\geq 36$ 248 years-old), race (white-brown/black-asian), education $(<12$ years/ $\geq 12$ years), occupation 249 (other/health professionals), self-reported oral health (good-excellent/regular-poor), time since last 250 dental visit ( $<1$ year/ $\geq 1$ year), and reason for dental utilization (prevention/treatment).

251 The predictive performance of the REALMD-20 for oral health outcomes was analyzed by 252 multivariate logistic regression models, which included only factors with significant Wald statistics 
253 in a prior univariate analysis. The factors were ordered into the models with basis on their Wald 254 statistics.

255 For all analyses, $P$ values $<0.05$ were considered significant.

256

\section{RESULTS}

258 The distribution of socio-demographic characteristics and oral health-related outcomes is presented 259 in Table 2. The sample was composed predominantly by women (55.5\%) and white-brown $260(85.5 \%)$ individuals, with an average age of 39.02 years old $( \pm 15.28$, median: 36.50$)$. The average 261 REALMD-20 score was 17.48 ( \pm 2.59 , median: 18.00, range 8-20), with the variance of 6.71. If 262 item deleted, the scale mean varied between 16.48 and 17.02, while the scale variance ranged from 2635.40 to 6.64 (Table 3). The instrument displayed a good internal consistency (Cronbach's alpha = 264 0.789), with values of Cronbach's alpha if item deleted varying between 0.765 and 0.791 (Table 3). 265 The test-retest reliability of the instrument was considered good (ICC $=0.73 ; 0.66-0.79,95 \% \mathrm{CI}$ ), 266 with a skewness of -1.63 and a kurtosis of 2.90. All participants read the easiest terms "Denture", 267 and "Hygiene" correctly, whereas only $46 \%$ of participants read the most difficult term "Jaundice" 268 without errors.

269 When the algorithm created for the original Rapid Estimate of Adult Literacy in Medicine 270 (REALM) [12] was used to categorize these participants in education grade levels, a lower 271 percentage was associated with adequate health literacy. Seventeen (8.5\%) participants scored at $2724^{\text {th }}-6^{\text {th }}$ grade level (range 6-13), 99 (49.5\%) participants scored at the $7^{\text {th }}$ to $8^{\text {th }}$ grade level (range 273 14-18), and 84 (42\%) participants scored at high school or more education level.

274 In the factor analysis, it was observed an adequate sample size $(\mathrm{KMO}=0.73)$ with a non-identity 275 correlation matrix (Bartlett's test of sphericity, $P<0.001$ ), and no influence of multicollinearity 276 (determinant $=0.004)$. Six factors with eigenvalues $>1.0$ were extracted: the factor I 277 (eigenvalue=4.53) comprised four terms - "Jaundice", "Amalgam", "Periodontitis" and 278 "Abscess"- accounted for $25.18 \%$ of total variance, while the factor II (eigenvalue $=1.88$ ) 279 comprised other four terms - "Gingivitis", "Instruction", "Osteoporosis" and "Constipation" 280 accounted for $10.46 \%$ of total variance. The first four factors accounted for $52.1 \%$ of total 281 variance. 
282 The REALMD-20 was positively correlated with the BREALD-30 $(R s=0.73, P<0.001)$ and BNFLI $283(R s=0.60, P<0.001)$. The average score $( \pm \mathrm{SD}$, range $)$ of the BREALD-30 and BNFLI were 24.75 $284( \pm 4.48,9-30)$ and $7.66( \pm 2.00,1-10)$, respectively. The REALMD-20 scores were significantly

285 higher among health professionals, more educated people, individuals who reported good/excellent 286 oral health conditions, and who sought preventive dental services. On the other hand, the scores 287 were similar between both groups of participants who visited a dentist within the last year and 288 those who visited a dentist at $\geq 1$ year (Table 4).

289 The REALMD-20 was a significant predictor of self-reported oral health status in a multivariate 290 logistic regression model, considering socio-demographic and oral health-related confounding 291 variables (Table 5).

292

\section{DISCUSSION}

294 To our knowledge, this is the first validation of the REALMD-20 in a non-English-speaking 295 country. Although focused on the analysis of two skills of health literacy, brief instruments as the 296 REALMD-20 are still suitable to rapidly recognize individuals with low health literacy in surveys 297 and clinics [32]. It might support the improvement of health outcomes through the promotion of 298 special education measures for deprived groups [7].

299 This version of the REALMD-20 showed an adequate internal consistency, since Cronbach's alpha $300>0.7$ are more adequate to the analysis of skill performance tools [33]. However, the Cronbach's 301 alpha was lower than the original REALMD-20. This coefficient varies across populations 302 according to the variation of item prevalences, which render problematic comparisons between 303 different samples [34]. The theory of reliability is summarized as $1-\left(\sigma^{2}{ }_{\mathrm{e}} / \sigma_{\mathrm{x}}^{2}\right)$, where $\sigma^{2}{ }_{\mathrm{e}}$ is the error 304 variance and $\sigma^{2}$ is the variance of the measure [35]. In this scenario, lower reliability estimates are 305 obviously obtained from more homogeneous samples. Therefore, these variations not necessarily 306 reflect true differences in reliability. Here, the variance (6.71) was significantly lower than that 307 described in the original study (10.56) [24]. It is expected that higher coefficients of reliability will 308 be observed in more heterogeneous population groups, e.g. residents of a city or a country. In this 309 sense, the structure of the twenty items generated after this adaptation process was maintained, 310 supported by the values of communalities and the reduction of scale variance if any item was 311 removed. Additionally, the skewness of this instrument indicates the most normal distribution of 
312 data compared to the original REALMD-20 (-2.32), REALM (-4.01) and REALM-D (-3.84)

313 [12,24], which contribute with its capacity of discrimination. Six subscales were evidenced by

314 EFA, with the detection of a major factor (2.41-fold greater than factor II), composed by the terms

315 with the highest reading difficulty, except for "Abscess". Therefore, health literacy measured by

316 the REALMD-20 is multidimensional.

317 The mean score observed in this study (17.48) was negligible higher than that previously described 318 by Gironda et al. [24] (17.28), especially when considering the same median value (18.0) achieved 319 by both studies. Interestingly, most of these participants (74.5\%) attended the school for a shorter 320 time than the expectancy for Brazilians (15 years) [36]. Then, the mean difference could be 321 explained by distinct socio-demographic characteristics between the participants from each 322 validation, although both groups of volunteers were recruited in dental clinics. The present sample 323 was composed exclusively by Brazilian Portuguese adult native speakers, with a median age 324 (36.50) close to that for total Brazilian population (31.60). Also, the distribution of age groups was 325 similar to that found in Brazil, with 21.5\% vs. 15.3\% (18-24 y), 61.0\% vs. 56.8\% (25-54 y), 11.0\% 326 vs. 11.5\% (55-64 y), and 6.5\% vs. 10.4\% (65+y) [36], corroborating with no influence of age 327 groups on the results of this validation. It was demonstrated that health literacy progressively 328 decreases toward older age groups, being young adults more prone to obtain health information 329 when engaged in health programs [37]. Likewise, the use of electronic sources as the Internet, 330 combined with the accessibility of information, contributes to greater health literacy levels among 331 young adults [37,38]. These present results indicate a greater proportion $(58 \%)$ of dental patients 332 with limited health literacy in comparison with the original study $(52.5 \%)$ [24].

333 The dichotomized categories of educational levels and races were significantly associated with the 334 capacity of reading health terms. As expected, health professionals presented higher REALMD-20 335 scores than other workers, which indicate the association of these outcomes with health knowledge 336 levels. These findings are consistent with other prior studies $[8,12,24,38]$. The convergent validity 337 of the REALMD-20 was performed with an oral health literacy tool (BREALD-30) $(R s=0.73)$ and 338 an instrument for analyzing the functional literacy of Brazilian citizens (BNFLI) $(R s=0.60)$. The 339 lack of a validated word recognition-based tool impeded this convergent analysis for medical 340 terms. The most similar instrument in this field, SAHLPA [19], is marked by a distinct framework 341 that requires the recognition and interpretation of words. 
342 The participants with good/excellent self-reported oral health status and users of preventive dental

343 services achieved higher REALMD-20 scores. In addition, health literacy and the type of

344 occupation were significant predictors of self-reported oral health status in a multiple logistic

345 regression model. Each one-point increase in the score of REALMD-20 indicates 34\% more

346 chance of an individual self-reporting a good-excellent oral health. These findings are supported by

347 the previous associations of low health literacy with poor oral health, more dental treatment needs

348 and overuse of emergency services [39]. On the other hand, REALMD-20 scores were not

349 associated with the periodicity of dental visits. The participants were dichotomized in $<1$ year and

$350 \geq 1$ year from their last dental visit, considering that $79 \%$ of them reported regular dental visits.

351 Although our results are in agreement with other authors [13,32,40], this issue presents divergent

352 outcomes. Calvasina et al. [41] showed that Brazilian immigrants who attended dental care

353 sporadically were nearly five times more likely to have inadequate oral health literacy than those

354 who visited a dentist annually or more often. It is noteworthy that our results could be influenced

355 by the inaccuracy of information provided by participants during the collection of oral health-

356 related information, which would be justified by memory errors and social desirability biases, i.e.,

357 when individuals deny some undesirable traits. This hypothesis gains strength if we consider that

358 dentists were responsible for interviewing the participants.

359 This study presents some limitations. First, as commonly observed in other validation studies

$360[8,12,18,19,24,29,31,32]$, the REALMD-20 was applied for a convenience sample that not reflects

361 the genuine structure of Brazilian demographics. It is inherent of this methodological approach that

362 excluded illiterates (7.4\% of total population) [36], and included a higher percentage of health

363 professionals $(11 \%)$ in relation to official statistics (1.4\%) [42]. This design is supported by two

364 main reasons: (a) the restriction of including only potential word readers, and (b) the need of

365 analysis of discriminant validity between health professionals and other workers. Second, the

366 proportion between males and females in adult ages was lower than that expected (0.80 vs. 0.94),

367 which could be explained by the recruitment of participants in dental clinics, since women are

368 more interested in seeking health care [43]. Third, the gratuity of dental services offered by our

369 public institution probably attracts a great percentage of patients living in areas of more vulnerable

370 social conditions, which corroborate with the lower proportion of white-brown participants

$371(85.5 \%)$ in relation to Brazilian demographics (90.8\%) [36]. Fourth, the great number of

372 investigators increases the risk of miscellaneous judgments on correct and incorrect readings. 
373 Although this possibility cannot be discarded, all efforts were directed to standardize the decision374 making process of all investigators, with previous discussion and training. Fifth, although this 375 instrument presented a good stability $(\mathrm{ICC}=0.73)$, its potential for detecting people with low health 376 literacy levels might be hampered in longitudinal studies, because the prior knowledge of words 377 could facilitate the reading over time. In this sense, the effect of previous awareness of words 378 might influence this analysis of stability, contributing to the decrease of ICC values. However, in 379 our opinion this situation was minimized by the observation of an interval of one month between 380 two applications. Finally, the predictive validation was established only on oral health-related 381 outcomes. In theory, general health conditions are also linked to health literacy levels; hence, 382 further studies must be developed to confirm the predictive value of this tool for systemic findings.

383 In conclusion, this Brazilian version of the REALMD-20 demonstrated adequate psychometric 384 properties for screening dental patients in relation to their recognition of health specific terms, 385 contributing to identify individuals with dental/medical vocabulary limitations for the improvement 386 of health education and outcomes in a person-centered care model. Further studies need to be carried out in order to validate the REALMD-20 for its application in distinct population groups.

\section{REFERENCES}

390

1. PovcalNet: an online analysis tool for global poverty monitoring [Internet]. Washington (DC): The World Bank; [updated 2016; cited 2016 Mar 18]. Available from: 392 http://iresearch.worldbank.org/PovcalNet/index.htm.

393 2. American Medical Association. Health literacy: report of the Council on Scientific Affairs. 394 JAMA. 1999;281:552-557.

3. Berkman ND, Sheridan SL, Donahue KE, Halpern DJ, Viera A, Crotty K, Holland A, Brasure M, Lohr KN, Harden E, Tant E, Wallace I, Viswanathan M. Health literacy interventions and outcomes: an updated systematic review. Evid Rep Technol Assess. 2011;199:1-941.

4. Brazilian National Functional Literacy Index [Internet]. São Paulo (SP): Instituto Paulo Montenegro; [updated 2015; cited 2015 January 10]. Available from: http://www.ipm.org.br/pt-br/Paginas/default.aspx. 
402 5. Sudore RL, Landefeld CS, Williams BA, Barnes DE, Lindquist K, Schillinger D. Use of a 403 modified informed consent process among vulnerable patients: a descriptive study. J Gen 404 Intern Med. 2006;21:867-873.

405

406

407

408

409

410

411

412

413

414

415

416

417

418

419

420

421

422

423

424

425

426

427

428

429

430

431

6. Stacey D, Légare F, Lewis K, Barry MJ, Bennett CL, Eden KB, Holmes-Rovner M, Llewellyn-Thomas H, Lyddiatt A, Thomson R, Trevena L. Decision aids for people facing health treatment or screening decisions. Cochrane Database Syst Rev. 2017;12:CD001431.

7. Miller TA. Health literacy and adherence to medical treatment in chronic and acute illness: a meta-analysis. Patient Educ Couns. 2016;99:1079-1086.

8. Lee JY, Rozier RG, Lee SY, Bender D, Ruiz RE. Development of a word recognition instrument to test health literacy in Dentistry: the REALD-30 - a brief communication. J Public Health Dent. 2007;67:94-98.

9. Friis K, Lasgaard M, Osborne RH, Maindal HT. Gaps in understanding health and engagement with healthcare providers across common long-term conditions: a population survey of health literacy in 29473 Danish citizens. BMJ Open. 2016;6:e009627.

10. Schiavo JH. Oral health literacy in the dental office: the unrecognized patient risk factor. J Dent Hyg. 2011;85:248-255.

11. Bress LE. Improving oral health literacy - the new standard in dental hygiene practice. J Dent Hyg. 2013;87:322-329.

12. Atchison KA, Gironda MW, Messadi D, Der-Martirosian C. Screening for oral health literacy in an urban dental clinic. J Public Health Dent. 2010;70:269-275.

13. Jamieson LM, Divaris K, Parker EJ, Lee JY. Oral health literacy comparisons between Indigenous Australians and American Indians. Community Dent Health. 2013;30:52-57.

14. Holtzman JS, Atchison KA, Gironda MW, Radbod R, Gombein J. The association between oral health literacy and failed appointments in adults attending a university-based general dental clinic. Community Dent Oral Epidemiol. 2014;42:263-270.

15. Cooper LA, Roter DL, Johnson RL, Ford DE, Steinwachs DM, Powe NR. Patient-centered communication, ratings of care, and concordance of patient and physician race. Ann Intern Med. 2003;139:907-915.

16. Altin SV, Finke I, Kautz-Freimuth S, Stock S. The evolution of health literacy assessment tools: a systematic review. BMC Public Health. 2014;14:1207. 
432 17. Parthasarathy DS, McGrath CP, Bridges SM, Wong HM, Yiu CK, Au TK. Efficacy of 433 instruments measuring oral health literacy: a systematic review. Oral Health Prev Dent. 434 2014;12:201-207.

435

436

437

438

439

440

441

442

443

444

445

446

447

448

449

450

451

452

453

454

455

456

457

458

459

460

461

462

18. Junkes MC, Fraiz FC, Sardenberg F, Lee JY, Paiva SM, Ferreira FM. Validity and Reliability of the Brazilian Version of the Rapid Estimate of Adult Literacy in Dentistry-BREALD-30. PLoS One. 2015;10:e0131600.

19. Apolinario D, Braga RCOP, Magaldi RM, Busse AL, Campora F, Brucki S, Lee SY. Short Assessment of Health Literacy for Portuguese-Speaking Adults. Rev Saúde Pública. 2012;46:702-711.

20. Tada A, Miura H. Association between mastication and cognitive status: a systematic review. Arch Gerontol Geriatr. 2017;70:44-53.

21. Artese HP, Foz AM, Rabelo MdeS, Gomes GH, Orlandi M, Suvan J, D'Aiuto F, Romito GA. Periodontal therapy and systemic inflammation in type 2 diabetes mellitus: a metaanalysis. PloS One. 2015;10:e0128344.

22. Dietrich T, Webb I, Stenhouse L, Pattni A, Ready D, Wanyonyi KL, White S, Gallagher JE. Evidence summary: the relationship between oral and cardiovascular disease. Br Dent J. 2017;222:381-385.

23. Martens L, De Smet S, Yusof MY, Rajasekharan S. Association between overweight/obesity and periodontal disease in children and adolescents: a systematic review and meta-analysis. Eur Arch Paediatr Dent. 2017;18:69-82.

24. Gironda M, Der-Martirosian C, Messadi D, Holtzman J, Atchison K. A brief 20-item dental/medical health literacy screen (REALMD-20). J Public Health Dent. 2013;73:50-55.

25. Herdman M, Fox-Rushby J, Badia X. A model of equivalence in the cultural adaptation of HRQoL instruments: the universalist approach. Qual Life Res. 1998;7:323-335.

26. Reichenheim ME, Moraes CL. Operationalizing the cross-cultural adaptation of epidemological measurement instruments. Rev Saúde Pública. 2007;41:665-673.

27. Department of Health and Human Services. Oral health in America: a report of the Surgeon General. J Calif Dent Assoc. 2000;28:685-695.

28. Pletneva N, Vargas A, Kalogianni K, Boyer C. Online health information search: what struggles and empowers the users? Results of an online survey. Stud Health Technol Inform. 2011;180:843-847. 
463 29. Lee SY, Stucky BD, Lee JY, Rozier RG, Bender DE. Short Assessment of Health Literacy464 Spanish and English: a comparable test of health literacy for Spanish and English speakers. 465 Health Serv Res. 2010;45:1105-1120.

466

467

468

469

470

471

472

473

474

475

476

477

478

479

480

481

482

483

484

485

486

487

488

489

490

491

492

493

30. Junkes MC. Translation, cross-cultural adaptation to Brazilian Portuguese, and validation of the Brazilian version of the REALD-30 (Rapid Estimate of Adult Literacy in Dentistry) [dissertation]. Curitiba (PR): Universidade Federal do Paraná; 2013.

31. Souza JG, Apolinario D, Farfel JM, Jaluul O, Magaldi RM, Busse AL, Campora F, JacobFilho W. Applicability of the Spoken Knowledge in Low Literacy Patients with diabetes in Brazilian elderly. Einstein. 2016;14:513-519.

32. Gong DA, Lee JY, Rozier RG, Pahel BT, Richman JA, Vann WF Jr. Development and testing of the Test of Functional Health Literacy in Dentistry (TOFHLiD). J Public Health Dent. 2007;67:105-112.

33. Kline P. The handbook of psychological testing. 2nd ed. London (UK): Routledge; 2000.

34. Teresi JA, Holmes D. Some methodological guidelines for cross-cultural comparisons. In: Skinner JH, Teresi JA, Holmes D, et al. Multicultural measurement in older populations. New York (NY): Springer Publishing Co.; 2002.

35. Lord FM, Novick MR. Statistical theories of mental test scores. Reading (MA): AddisonWesley Publishing Co.; 1968.

36. The World Factbook [Internet]. Washington (DC): Central Intelligence Agency; [updated 2017; cited 2017 Jul 04]. Available from: https://www.cia.gov/library/publications/theworld-factbook/geos/br.html

37. Neter E, Brainin E. eHealth literacy: extending the digital divide to the realm of health information. J Med Internet Res. 2012;14:e19.

38. Sun X, Shi Y, Zeng Q, Wang Y, Du W, Wei N, Xie R, Chang C. Determinants of health literacy and health behavior regarding infectious respiratory diseases: a pathway model. BMC Public Health. 2013;13:261.

39. Burgette JM, Lee JY, Baker AD, Vann WF Jr. Is dental utilization associated with oral health literacy? J Dent Res. 2016;95:160-166.

40. Griffey RT, Kennedy SK, D'Agostino McGowan L, Goodman M, Kaphingst KA. Is low health literacy associated with increased emergency department utilization and recidivism? Acad Emerg Med. 2014;21:1109-1115. 
494 41. Calvasina P, Lawrence HP, Hoffman-Goetz L, Norman CD. Brazilian immigrants' oral 495 health literacy and participation in oral health care in Canada. BMC Oral Health. $496 \quad 2016 ; 16: 18$.

497 42. Knoema [Internet]. Washington (DC): World Health Organization; [updated 2011; cited 4982017 Jul 04]. Available from: https://knoema.com/WHOSDB/world-health-organization499 statistics-database?Location=1000260-brazil\&Category=1000010-human-resources-for$500 \quad$ health

501 43. Thompson AE, Anisimowicz Y, Miedema B, Hogg W, Wodchis WP, Aubrey-Bassler K. 502 The influence of gender and other patient characteristics on health-care seeking behaviour: a 503 QUALICOPC study. BMC Fam Pract. 2016;17:38.

504

505 


\section{Table $\mathbf{1}$ (on next page)}

The Brazilian version of the 20-item Rapid Estimate of Adult Literacy in Medicine and Dentistry (REALMD-20). The English original terms are presented in parentheses. 
1 The Brazilian version of the 20-item Rapid Estimate of Adult Literacy in Medicine and Dentistry 2 (REALMD-20). The English original terms are presented in parentheses

\begin{tabular}{ll}
\hline REALMD-20 & List 2 \\
\hline List 1 & Extração (Extraction) \\
\hline Cárie (Caries) & Abscesso (Abscess) \\
Dentadura (Denture) & Instrução (Directed) \\
Higiene (Hygiene) & Colite (Colitis) \\
Fadiga (Fatigue) & Constipação (Constipation) \\
Anemia (Anemia) & Osteoporose (Osteoporosis) \\
Cálculo (Calculus) & Gengivite (Gingivitis) \\
Convênio (Insurance) & Amálgama (Amalgam) \\
Alérgico (Allergic) & Periodontite (Periodontitis) \\
Depressão (Depression) & Icterícia (Jaundice) \\
Anestesia (Anesthetic) & \\
\hline
\end{tabular}

3

4

5

6

7

8

9

10

11

12

13

14

15

16

17

18

19

20

21

22

23

24

25

26

27

28

29

30

31

32

33

34

35

36 
Table 2 (on next page)

The distribution of participants by socio-demographic characteristics and oral healthrelated aspects. 
1 The distribution of participants by socio-demographic characteristics and oral health-related aspects

\begin{tabular}{lr}
\hline & \multicolumn{1}{c}{$\mathbf{n ~ ( \% )}$} \\
\hline Gender & \\
Male & $89(44.5 \%)$ \\
Female & $111(55.5 \%)$ \\
& \\
Race & \\
White-Brown & \\
Black & $171(85.5 \%)$ \\
Asian & $28(14.0 \%)$ \\
& $1(0.5 \%)$
\end{tabular}

\section{Education}

$\leq 8$ th grade

9 - 12th grade

$59(29.5 \%)$

College

$90(45.0 \%)$

Post Graduate

$37(18.5 \%)$

$14(7.0 \%)$

\section{Occupation}

Other

Health technician

$178(89.0 \%)$

Health professional

$6 \quad(3.0 \%)$

$16(8.0 \%)$

Self-reported oral health

Excellent

Very Good

$21(10.5 \%)$

$23(11.5 \%)$

Good

Regular

$68(34.0 \%)$

$65(32.5 \%)$

Poor

$21(10.5 \%)$

Do not know/do not answer

$2(1.0 \%)$

Time since last dental visit

$<1$ year

1-2 years

$158(79.0 \%)$

$20(10.0 \%)$

2-5 years

$>5$ years

$14(7.0 \%)$

$7 \quad(3.5 \%)$

Do not know/do not answer

$1(0.5 \%)$

Reason for dental utilization

4

5

6

7

8

9

10

11

12

13

14 


\section{Table 3 (on next page)}

Communalities $\left(\mathrm{h}^{2}\right)$ and scale means, scale variances and Cronbach's alpha if item deleted from the Brazilian version of the REALMD-20. 
1 Communalities $\left(\mathrm{h}^{2}\right)$ and scale means, scale variances and Cronbach's alpha if item deleted from the 2 Brazilian version of the REALMD-20

3

\begin{tabular}{lcccc}
\hline Item & $\begin{array}{c}\text { Scale mean if } \\
\text { item deleted }\end{array}$ & $\begin{array}{c}\text { Scale variance } \\
\text { if item deleted }\end{array}$ & $\begin{array}{c}\text { Cronbach's alpha } \\
\text { if item deleted }\end{array}$ & $\mathbf{h}^{\mathbf{2}}$ \\
\hline Caries & 16.49 & 6.64 & & \\
Denture & 16.48 & 6.61 & 0.791 & 0.58 \\
Hygiene & 16.48 & 6.61 & 0.789 & 0.93 \\
Fatigue & 16.49 & 6.55 & 0.789 & 0.74 \\
Anemia & 16.50 & 6.44 & 0.784 & 0.75 \\
Calculus & 16.51 & 6.17 & 0.774 & 0.86 \\
Covenant & 16.49 & 6.49 & 0.785 & 0.76 \\
Allergic & 16.53 & 6.27 & 0.782 & 0.76 \\
Depression & 16.49 & 6.54 & 0.786 & 0.68 \\
Anesthetic & 16.54 & 6.09 & 0.775 & 0.86 \\
Extraction & 16.50 & 6.44 & 0.784 & 0.65 \\
Abscess & 16.68 & 5.82 & 0.780 & 0.73 \\
Instruction & 16.54 & 6.25 & 0.782 & 0.40 \\
Colitis & 16.56 & 5.99 & 0.773 & 0.59 \\
Constipation & 16.64 & 5.63 & 0.766 & 0.64 \\
Osteoporosis & 16.68 & 5.50 & 0.765 & 0.47 \\
Gingivitis & 16.58 & 5.80 & 0.767 & 0.51 \\
Amalgam & 16.96 & 5.40 & 0.776 & 0.71 \\
Periodontitis & 16.91 & 5.44 & 0.778 & 0.54 \\
Jaundice & 17.02 & 5.46 & 0.779 & 0.43 \\
\hline
\end{tabular}


Table 4(on next page)

Comparison of average ( \pm SD) and medians of the REALMD-20 scores between dichotomized socio-demographic and oral health-related variables (U-Mann Whitney test, $P<0.05)$. 
1 Comparison of average ( \pm SD) and medians of the REALMD-20 scores between dichotomized socio-

2 demographic and oral health-related variables (U-Mann Whitney test, $P<0.05$ ).

\begin{tabular}{lccc} 
& Average $( \pm \mathrm{SD})$ & Median (Min-Max) & $\boldsymbol{P}$ \\
\hline Gender & & & \\
Male & $17.66 \pm 2.50$ & $18.00(8-20)$ & \\
Female & $17.33 \pm 2.66$ & $18.00(8-20)$ & 0.32 \\
\hline Race & & & \\
White-Brown & $17.64 \pm 2.51$ & $18.00(8-20)$ & \\
Black-Asian & $16.52 \pm 2.91$ & $17.00(9-20)$ & 0.03 \\
\hline Education & & & \\
$<12$ years & $16.94 \pm 2.74$ & $17.50(8-20)$ & \\
$\geq 12$ years & $19.02 \pm 1.16$ & $19.00(16-20)$ & $<0.001$ \\
\hline Occupation & & & \\
Other professionals & $17.24 \pm 2.63$ & $18.00(8-20)$ & \\
Health professionals & $19.45 \pm 0.74$ & $20.00(18-20)$ & $<0.001$ \\
\hline Self-reported oral health & & & \\
Good - Excellent & $18.34 \pm 1.78$ & $19.00(12-20)$ & \\
Do not Know - Regular & $16.39 \pm 3.02$ & $17.00(8-20)$ & $<0.001$ \\
\hline Time since last dental visit & & & \\
$<1$ year & $17.58 \pm 2.56$ & $18.00(8-20)$ & \\
$\geq 1$ year & $17.10 \pm 2.70$ & $18.00(9-20)$ & 0.22 \\
\hline Reason for dental utilization & & & \\
Prevention & $18.09 \pm 2.16$ & $19(10-20)$ & \\
Treatment & $17.17 \pm 2.74$ & $18(8-20)$ & 0.01 \\
\hline
\end{tabular}




\section{Table 5 (on next page)}

Logistic regression models for predictive factors of self-reported oral health status and reason for dental utilization. 
1 Logistic regression models for predictive factors of self-reported oral health status and reason for dental 2 utilization

\begin{tabular}{|c|c|c|c|c|c|}
\hline & $\mathbf{B}^{*}$ & S.E. ${ }^{\dagger}$ & Wald & $\boldsymbol{P}$ & $\mathbf{O R}$ \\
\hline \multicolumn{6}{|l|}{ Self-reported oral health: Good-Excellent } \\
\hline REALMD-20 & 0.29 & 0.08 & 12.66 & $<0.001$ & 1.34 \\
\hline Education ( $\geq 12$ years) & 0.37 & 0.43 & 0.73 & 0.394 & 1.45 \\
\hline Occupation (Health professional) & 1.51 & 0.82 & 3.41 & 0.065 & 4.52 \\
\hline Age & -0.03 & 0.01 & 5.34 & 0.021 & 0.98 \\
\hline Time since last dental visit $(<1$ y) & 0.86 & 0.40 & 4.57 & 0.033 & 2.36 \\
\hline Constant & -4.73 & 1.47 & 10.30 & 0.001 & 0.01 \\
\hline \multicolumn{6}{|l|}{ Reason for dental utilization: Prevention } \\
\hline Oral health (Good-Excellent) & 0.88 & 0.37 & 5.81 & 0.016 & 2.41 \\
\hline Education ( $\geq 12$ years) & 0.52 & 0.39 & 1.72 & 0.190 & 1.67 \\
\hline Time since last dental visit $(<1$ y) & 0.99 & 0.47 & 4.56 & 0.033 & 2.70 \\
\hline Occupation (Health professional) & 0.63 & 0.54 & 1.34 & 0.247 & 1.87 \\
\hline REALMD-20 & 0.03 & 0.08 & 0.14 & 0.709 & 1.03 \\
\hline Constant & -2.76 & 1.34 & 4.22 & 0.040 & 0.06 \\
\hline
\end{tabular}

*Unstandardized coefficient

†Standard error

3

†dds ratio

4

5

8 